\title{
Research Paper: Intra- and Inter-Rater Reliability of Micro Manual Muscle Tester of the Lower Extremity in Children With Diplegia Cerebral Palsy
}

\author{
Masoud Gharib ${ }^{1}$, Roshanak Vameghi ${ }^{* *}$ (D), Mahyar Salavati ${ }^{3}$, Seyed Ali Hosseini² ${ }^{2}$ Ahmad Saeedi $^{4}$ \\ 1. Department of Rehabilitation, Faculty of Paramedicine, Mazandaran University of Medical Sciences, Sari, Iran. \\ 2. Pediatric Neurorehabilitation Research Center, University of Social Welfare and Rehabilitation Sciences, Tehran, Iran. \\ 3. Department of Physiotherapy, University of Social Welfare and Rehabilitation Sciences, Tehran, Iran. \\ 4. Department of Statistical Research and Information Technology, Institute for Research and Planning in Higher Education, Tehran, Iran.
}

\begin{tabular}{|c|c|}
\hline $\begin{array}{l}\text { Use yourd device to scan } \\
\text { and read the article online }\end{array}$ & \\
\hline 口ifipra & $\begin{array}{l}\text { Muscle Tester of the Lower Extremity in Children With Diplegia Cerebral Palsy. Iranian Rehabilitation Journal. 2019; } 17(2): 165- \\
\text { 170. http://dx.doi.org/10.32598/irj.17.2.165 }\end{array}$ \\
\hline 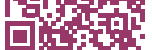 & doij http://dx.doi.org/10.32598/irj.17.2.165 \\
\hline
\end{tabular}

Article info:

Received: 15 Dec 2018

Accepted: 28 Feb 2019

Available Online: 01 June 2019

Keywords:

Muscles, Reliability, Cerebral Palsy

\section{A B S T R A C T}

Objectives: The Micro Manual Muscle Tester (MMMT) is a Hand-Held Dynamometer (HHD). The current study aimed to evaluate the intra- and inter-rater reliability of this device.

Methods: To determine the reliability of the MMMT, two previously trained assessors to work with HHD performed HHD measurements on 7 muscle groups of the lower extremities (hip flexors, hip extensors, hip abductors, knee extensors, knee flexors, ankle plantar-, and dorsiflexors) using the make-test method. The study participants were evaluated thrice by two occupational therapists in 10 separate days.

Results: All the inter- and intra-correlations were reported as excellent (ICC $>0.90)$, except for $\mathrm{ICC}_{23}$ in the hip flexor muscles; and $\mathrm{ICC}_{23}$ in the dorsiflexor muscles that were similarly good $(\mathrm{ICC}=0.75-0.89)$ at a high significance level $(\mathrm{P}<0.001)$.

Discussion: The MMMT had an acceptable reliability. Furthermore, this device is useful for investigating changes in strength after rehabilitation interventions. 


\section{Highlights}

- Evaluating muscle power can affect clinical practices and research studies on children who have cerebral palsy.

- Strength training programs for children with cerebral palsy can affect their walking abilities.

- Reliability is crucial in assessing muscle strength, and it depends on the quality of measurements.

\section{Plain Language Summary}

Muscle power plays an important role in the motor ability of children with cerebral palsy. Assessment of muscle strength is one of the most common assessments in rehabilitation interventions for children with cerebral palsy. Typically, this assessment is performed by manual assessment, which is a subjective method. The micro manual muscle tester is an objective tool for measuring muscle strength. We measured the reliability of micro manual muscle tester with two evaluators.

\section{Introduction}

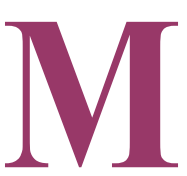

uscle weakness has long been reported among children with Cerebral Palsy (CP); however, they were ignored for decades in rehabilitation interventions, due to the difficulty to increase their spasticity by strength therapy [1]. Thus, evaluating muscle power can majorly impact clinical practices and research studies on children suffering from CP. Strength training programs for children with CP can affect their walking abilities [2-6].

In clinics, muscle strength is commonly assessed by Manual Muscle Testing (MMT) methods. The MMT scores range from 0 to 5; it is recognized as a subjective measure, strongly dependent on clinicians' education and experience $[7,8]$. Additionally, Handheld Dynamometer (HHD) is an objective tool for measuring muscle strength. It is a small internal force cell able of measuring muscular power (newton or kilogram) $[9,10]$.

Moreover, HHD has better sensitivity and inter-rater reliability, than MMT in terms of recognizing strength deficits $[11,12]$. In HHD approach, the tool is held in the hand of the tester [9]. Furthermore, two techniques have been explained in the literature for using this device. In the break-test method, the assessor pushes against the subject's extremities and the subject's maximal muscular effort is dominant; thus, an isotonic contraction is produced.

In the make-test method, the assessor holds the dynamometer static, while the subject makes use of a maximal load against it and produces an isometric contraction $[13,14]$. A high Intraclass Correlation Coefficient
(ICC) has been reported for its test-retest reliability by Ayalon in children with CP [15].

Taylor et al. also measured 10 spastic diplegic CP cases, from 1 to 2 weeks, separately. They assessed the reliability of 5 lower-extremity muscle groups: hip flexors, extensors, abductors, knee extensors, and plantar flexors [16]. Berry et al. examined muscle power for one to two weeks individually in 15 diplegic and quadriplegic $\mathrm{CP}$ children from three muscle groups, as follows: hip abductors, flexors and knee extensors. Both studies demonstrated good to high inter- and intra-rater reliability of the tool [17].

Reality is decisive when assessing muscle strength in clinical conditions; it depends on the quality of measurements. In addition to validity, another necessity of measurements is their consistency. It concerns with the issue that a test can be reliably administered by different examiners [18]. The Micro Manual Muscle Tester (MMMT) is a type of HHD; therefore, the present study aimed to assess the intra- and inter-rater reliability of this device.

\section{Methods}

This cross-sectional psychometric study was performed on a convenience sample of 26 (17 boys and 9 girls) children with spastic diplegic CP (leg-dominant bilateral spasticity) diagnosed by a pediatric neurologist. The Mean \pm SD age of subjects was $11.10 \pm 2.14$ years. They were selected from a private clinic (Zehne Pooya).

The study participants reported no orthopedic or spasticity-reducing intermediation (likewise, surgery and botulinum toxin A injections) in the past year. They were 
Table 1. Muscle test positions

\begin{tabular}{cccc}
\hline Muscle Group & Posture & Subject Position & MMMT Position \\
\hline Hip flexors* & Sitting & Hip flexed $90^{\circ}$ off the surface & Aanterior to the mid-thigh \\
Hip extensors* & Supine & Hip flexed $90^{\circ}$ & Posterior to the mid-thigh \\
Hip abductors** & Supine & $\begin{array}{c}\text { Hips in a neutral position and } \\
00 \text { abduction/adduction }\end{array}$ & Lateral side mid-thigh \\
Knee flexors** & Sitting & Knee and hip flexed 900 & Posteriorly 5 cm proximal to lateral malleoli \\
Knee extensors** & Sitting & Knee and hip flexed 900 & Anteriorly 5 cm proximal to lateral malleoli \\
Ankle plantar flexors** & Supine & Knee extended & Dorsum surface of metatarsal heads \\
Ankle dorsiflexors*** & Supine & Knee extended & The plantar surface of metatarsal heads \\
\hline
\end{tabular}

Пranian Rehabilitation Journal

*Muscle test positions according to Hislop and Montgomery, Muscle test positions reported by Olaf et al.; ** Muscle test positions by Berry et al.; and ${ }^{* * *}$ Muscle test positions based on Wiley and Damiano

capable of following instructions and collaborating with the examiner. Their range of motions was sufficient for participation in the study and were allowed for performing the test positions (Table 1). Furthermore, the study received an ethical approval from the University of Social Welfare and Rehabilitation Sciences, Iran.

Prior to the test, the height and weight of each child was measured to characterize their Body Mass Index (BMI). The study participants were also evaluated thrice by two occupational therapists, on 10 separate days. The testing sessions were similarly conducted in a private clinic. To investigate the reliability of the MMMT, two previously trained assessors for HHD, established HHD measurements on 7 muscle groups of the subjects' lower limb (hip flexors, hip extensors, hip abductors, knee extensors, knee flexors, ankle plantar-, and dorsiflexors) using the make-test method. Three minutes of rest was also given after evaluating each muscle group. The position of testing approach was modified according to Hislop et al., Olaf et al., Berry et al., and Wiley et al., studies [1, 17, 19, 20].

In the first session; the first evaluator performed measurements alone and 10 days later, in the second session, two assessors simultaneously evaluated the subjects' muscle strength. Upon the completion of the first evaluator's assessment, the second evaluator began the procedure and the interval between the two evaluations was 10 minutes. Both assessors were blind to the power scores obtained from the earlier examination session. The two assessors were also experienced pediatric occupational therapists and needed training to use the HHD.

Strength was assessed via the portable device of the MMMT (by North Cost Medical Inc., USA). This device was purchased from Noavaran Company in Iran. Other specifications were as follows: the size of $200 \mathrm{~mm}$, the weight of $630 \mathrm{gr}$, weight range from 0 to $50 \mathrm{~kg}(110$ pounds), the accuracy of $0.1 \mathrm{~kg}$, and a resolution of $0.1 \mathrm{~kg}$.

The position of the tester was standardized for each assessment. A make-test method was used with the examiner setting a permanent resistive load for $5 \mathrm{~s}$; it was perpendicularly directed to evoke an isometric muscle contraction. An instruction of 'press as strong as you can' was also given to each child for each examination.

Each child was similarly allowed to practice the trial before evaluating each muscle group. In addition, two trials were performed for each muscle group and the highest strength was recorded. Additional practice trials were also allowed, if necessary. The power score for each participant was obtained by averaging the right and left sided scores for each muscle group. The strength was then computed in kilograms.

An estimate of intra- and inter-rater reliability was managed using test-retest reliability for ICC. The point approximation of the ICC values for reliability analyses was suggested as high $(>0.90)$, good (0.75-0.89), medium (0.50$0.74)$, or low $(<0.50)$, according to Portney and Watkins [21]. The significance level was set at 0.05 .

The first measurement of the assessor 1 and the second assessment by the same assessor (after 10 days) were considered as intra-rater reliability $\left(\mathrm{ICC}_{2,1}\right)$. In addition, the first and second assessments of assessor 1 and assessor 2 were considered as inter-rater reliability $\left(\mathrm{ICC}_{1,3}\right),\left(\mathrm{ICC}_{2,3}\right)$.

\section{Results}

The study participants' demographic characteristics are illustrated in Table 2. Accordingly, 26 children (17 boys and 9 girls) with CP participating in this study had 
a Mean \pm SD age of $133.30 \pm 25.77$ months. Moreover, the Gross Motor Function Classification System (GMFCS) levels were classified as follows: level $1=8(30.8)$; level $2=6(23.1)$; level $3=6(23.1)$; and level $4=6(23.1)$. No significant difference was reported between the subjects' BMIs after one week $(\mathrm{P}>0.05)$.

As Table 3, the lowest strength score was generally observed in the ankle dorsiflexor muscles $(1.73 \pm 1.02)$ and the highest strength was generally observed in the hip flexors (4.14 \pm 1.61$)$. Moreover, the greatest difference between times of assessment in the mean strength score was obtained in the knee extensor muscles in the second (3.01 \pm 2.09$)$ and third (2.72 \pm 1.75$)$ assessments.

Table 4 indicates ICCs inter- and intra-correlations. All inter- and intra-correlations were reported as excellent (ICC $>0.90$ ), except for $\mathrm{ICC}_{2,3}$ in the hip flexor muscles;
$\mathrm{ICC}_{2,3}$ in dorsiflexor muscles were also reported as good (ICC $=0.75-0.89)$ at a high significance level $(\mathrm{P}<0.001)$.

\section{Discussion}

The inter- and intra-rater reliability of muscle strength measurements in a group of children suffering from CP suggested acceptable correlations; therefore, the MMMT is reliable for measuring muscle strength changes in children with diplegic CP. Therefore, it is probably effective for therapists and researchers interested in measuring the influence of power training planning over time in individuals with diplegic $\mathrm{CP}$ [16]. Rehabilitation programs require reliable measurement devices. For instance, it is important for a therapist to see if the strength of the muscles is actually improved or it is because of pharmaceutical errors $[22,23]$. Moreover, inappropriate or low selective control in several muscle groups may impede the person's ability

Table 2. The study participants' demographic characteristics

\begin{tabular}{|c|c|c|}
\hline \multicolumn{2}{|c|}{ Variable } & No. $(\%)$ or Mean \pm SD \\
\hline \multicolumn{2}{|c|}{ Children's age (months) } & $133.30 \pm 25.77$ \\
\hline \multirow{2}{*}{ Gender } & Male & 17(65.4) \\
\hline & Female & 9(34.6) \\
\hline \multirow{4}{*}{$\begin{array}{l}\text { Gross Motor Function Classification System } \\
\text { (GMFCS) }\end{array}$} & Level 1: They walk and climb stairs without limitations & $8(30.8)$ \\
\hline & Level 2: They walk with limitations & 6(23.1) \\
\hline & Level 3: They walk with assistive devices & $6(23.1)$ \\
\hline & Level 4: They are unable to walk; limited self-mobility & $6(23.1)$ \\
\hline \multicolumn{2}{|c|}{$\mathrm{BMI}\left(\mathrm{kg} / \mathrm{m}^{2}\right)$} & $18.18 \pm 4.26$ \\
\hline
\end{tabular}

Iranian Rehabilitation Journal

Table 3. The Mean \pm SD scores of measurements for muscle group strength using the MMMT on participation

\begin{tabular}{|cccccc}
\hline Muscle Group & \multicolumn{3}{c}{ Mean \pm SD } & No \\
\cline { 2 - 5 } & Test 1 & Test 2 & Test 3 & Median \\
\hline Hip flexors & $4.04 \pm 1.63$ & $4.15 \pm 1.71$ & $4.23 \pm 1.50$ & $4.14 \pm 1.61$ & 26 \\
Hip extensors & $3.04 \pm 1.87$ & $3.30 \pm 1.65$ & $3.50 \pm 1.84$ & $3.28 \pm 1.78$ & 26 \\
\hline Hip abductors & $2.01 \pm 1.36$ & $2.28 \pm 1.55$ & $2.20 \pm 1.45$ & $2.16 \pm 1.45$ & 26 \\
\hline Knee flexors & $3.52 \pm 2.15$ & $3.31 \pm 1.65$ & $3.50 \pm 1.84$ & $3.44 \pm 1.88$ & 26 \\
\hline Knee extensors & $2.96 \pm 2.06$ & $3.01 \pm 2.09$ & $2.72 \pm 1.75$ & $2.89 \pm 1.96$ & 26 \\
\hline Ankle plantar flexors & $2.79 \pm 2.09$ & $2.54 \pm 1.76$ & $2.60 \pm 1.73$ & $2.64 \pm 1.86$ & 26 \\
\hline Ankle dorsiflexors & $1.79 \pm 1.09$ & $1.74 \pm 1.06$ & $1.68 \pm 0.92$ & $1.73 \pm 1.02$ & 26
\end{tabular}


Table 4. The inter- and intra-rater reliability of muscle group power measurements using the MMMT in children with diplegic $\mathrm{CP}$

\begin{tabular}{cccccc}
\hline \multirow{2}{*}{ Muscle Group } & Intra-Rater Reliability (95\%Cl) & Inter-Rater Reliability (95\%Cl) & P & df \\
\cline { 2 - 5 } & ICC $_{1,2}$ & ICC $_{2,3}$ & ICC $_{1,3}$ & & \\
\hline Hip flexors & $0.940(0.866-0.973)$ & $0.858(0.684-0.936)$ & $0.923(0.829-0.966)$ & $<0.001$ & 25 \\
Hip extensors & $0.970(0.932-0.986)$ & $0.945(0.878-0.975)$ & $0.957(0.905-0.981)$ & $<0.001$ & 25 \\
Hip abductors & $0.954(0.896-0.979)$ & $0.914(0.809-0.962)$ & $0.961(0.914-0.983)$ & $<0.001$ & 25 \\
Knee flexors & $0.973(0.939-0.988)$ & $0.960(0.911-0.982)$ & $0.958(0.905-0.981)$ & $<0.001$ & 25 \\
Knee extensors & $0.968(0.929-0.986)$ & $0.938(0.862-0.972)$ & $0.960(0.910-0.982)$ & $<0.001$ & 25 \\
Ankle plantar flexors & $0.975(0.945-0.989)$ & $0.958(0.906-0.981)$ & $0.973(0.940-0.988)$ & $<0.001$ & 25 \\
Ankle dorsiflexors & $0.938(0.862-0.972)$ & $0.895(0.767-0.953)$ & $0.902(0.782-0.956)$ & $<0.001$ & 25 \\
\hline
\end{tabular}

Iranian Rehabilitation Journal

to perform activities [24]. This was clearly observed in the subjects' ankle dorsiflexor muscles, which was consistent with the findings of Olaf et al. [20].

The intra- and inter-rater reliability of micro manual muscle tester of the HHD in the subjects with CP was reported as acceptable. Therefore, it is suggested to use the selfsame assessor when linear measurements are accomplished. In this study, the make-test method was employed for assessing muscle groups. Olaf et al. also reported that the maketest method was more reliable than the break-test one for measuring muscle strength in people with $\mathrm{CP}$; although the inter-rater reliability of the HHD was low [20]. Thus, it is suggested to use the selfsame examiner whenever the HHD is the preferred muscle power test procedure.

In this research, only children suffering from diplegia $\mathrm{CP}$ were examined. However, there is a variety of children with $\mathrm{CP}$ referring to clinics. Future studies are suggested to examine the different types of CP and motor mobility. Muscle strength tests can be also influenced by patients' motivation or cooperation [25]; unfortunately, recognition of children participating in this study was not formally determined although they had no clear cognitive problems. Furthermore, another positioning of the limbs suggested in some studies was not used in the present research. This is because we assumed some positioning might decrease the patients' cooperation or lead to an unrealistic increase in isometric muscle contractions.

\section{Conclusion}

The MMMT had an acceptable reliability for testing hip flexors, hip extensors, hip abductors, knee flexors and extensors, dorsi-, and plantar flexors in the illustrated positions.

\section{Ethical Considerations}

\section{Compliance with ethical guidelines}

The study was conducted following the instructions issued by the Declaration of Helsinki (2008): The participants were briefed on the study both verbally and in writing; The study participants provided written informed consent forms prior to the interviews; To protect their privacy and confidentiality, all data were recorded anonymously.

\section{Funding}

The present paper was extracted from the first author' thesis, in Department of Rehabilitation, Faculty of Paramedicine, Mazandaran University of Medical Sciences, Sari, Iran.

\section{Authors' contributions}

Conceptualization: Masoud Gharib, Roshanak Vameghi, Mahyar Salavati; Methodology: Masoud Gharib, Roshanak vameghi, Mahyar Salavati, Seyed Ali Hosseini, Ahmad Saeedi; Interviews: Saeed Shahabi; Writing-originl draft: Masoud Gharib; Writing-review and editing: All authors; and Supervision: Masoud Gharib, Roshank Vameghi.

\section{Conflict of interest}

The authors declared no conflict of interest. 


\section{References}

[1] Wiley ME, Damiano DL. Lower-extremity strength profiles in spastic Cerebral Palsy. Developmental Medicine \& Child Neurology. 1998; 40(2):100-7. [DOI:10.1111/j.1469-8749.1998.tb15369.x]

[2] Damiano DL, Vaughan CL, Abel ME. Muscle response to heavy resistance exercise in children with spastic Cerebral Palsy. Developmental Medicine \& Child Neurology. 1995; 37(8):731-9. [DOI:10.1111/j.1469-8749.1995.tb15019.x]

[3] Damiano DL, Abel MF. Functional outcomes of strength training in spastic Cerebral Palsy. Archives of Physical Medicine and Rehabilitation. 1998; 79(2):119-25. [DOI:10.1016/S00039993(98)90287-8]

[4] Taylor NF, Dodd KJ, Baker RJ, Willoughby K, Thomason P, Graham HK. Progressive resistance training and mobility-related function in young people with Cerebral Palsy: A randomized controlled trial. Developmental Medicine \& Child Neurology. 2013; 55(9):806-12. [DOI:10.1111/dmcn.12190] [PMID]

[5] Ross SM, MacDonald M, Bigouette JP. Effects of strength training on mobility in adults with Cerebral Palsy: A systematic review. Disability and Health Journal. 2016; 9(3):375-84 [DOI:10.1016/j.dhjo.2016.04.005] [PMID]

[6] Thompson N, Stebbins J, Seniorou M, Newham D. Muscle strength and walking ability in diplegic Cerebral Palsy: Implications for assessment and management. Gait \& posture. 2011; 33(3):321-5. [DOI:10.1016/j.gaitpost.2010.10.091] [PMID]

[7] Fenter PC, Bellew JW, Pitts T, Kay R. A comparison of 3 handheld dynamometers used to measure hip abduction strength. The Journal of Strength \& Conditioning Research. 2003; 17(3):531-5. [DOI:10.1519/00124278-200308000-00018]

[8] Trudelle-Jackson E, Jackson AW, Frankowski CM, Long KM, Meske NB. Interdevice reliability and validity assessment of the Nicholas hand-held dynamometer. Journal of Orthopaedic \& Sports Physical Therapy. 1994; 20(6):302-6. [DOI:10.2519/ jospt.1994.20.6.302] [PMID]

[9] Bohannon R. Muscle strength testing with hand-held dynamometers. Muscle strength testing: Instrumented and noninstrumented systems. London: Churchill Livingstone; 1990.

[10] Bohannon R. Manual muscle test scores and dynamometer test scores of knee extension strength. Archives of Physical Medicine and Rehabilitation. 1986; 67(6):390-2. [PMID]

[11] Roebroeck ME, Harlaar J, Lankhorst GJ. Reliability assessment of isometric knee extension measurements with a computerassisted hand-held dynamometer. Archives of Physical Medicine and Rehabilitation. 1998; 79(4):442-8. [DOI:10.1016/S0003 9993(98)90147-2]

[12] Kwoh CK, Petrick MA, Munin MC. Inter-rater reliability for function and strength measurements in the acute care hospital after elective hip and knee arthroplasty. Arthritis \& Rheumatology. 1997; 10(2):128-34. [DOI:10.1002/art.1790100208]

[13] Bohannon RW. Make tests and break tests of elbow flexor muscle strength. Physical Therapy. 1988; 68(2):193-4. [DOI:10.1093/ ptj/68.2.193] [PMID]

[14] Van der Ploeg R, Oosterhuis H. The "make/break test" as a diagnostic tool in functional weakness. Journal of Neurology, Neurosurgery \& Psychiatry. 1991; 54(3):248-51. [DOI:10.1136/ jnnp.54.3.248] [PMID] [PMCID]
[15] Ayalon M, Ben-Sira D, Hutzler Y, Gilad T. Reliability of isokinetic strength measurements of the knee in children with Cerebral Palsy. Developmental Medicine and Child Neurology. 2000; 42(6):398-402. [DOI:10.1017/S0012162200000724] [PMID]

[16] Taylor NF, Dodd KJ, Graham HK. Test-retest reliability of hand-held dynamometric strength testing in young people with Cerebral Palsy. Archives of Physical Medicine and Rehabilitation. 2004; 85(1):77-80. [DOI:10.1016/S0003-9993(03)00379-4]

[17] Berry ET, Giuliani CA, Damiano DL. Intrasession and intersession reliability of handheld dynamometry in children with Cerebral Palsy. Pediatric Physical Therapy. 2004; 16(4):191-8. [DOI:10.1097/01.PEP.0000145932.21460.61] [PMID]

[18] de Vet HC, Terwee CB, Knol DL, Bouter LM. When to use agreement versus reliability measures. Journal of Clinical Epidemiology. 2006; 59(10):1033-9. [DOI:10.1016/j.jclinepi.2005.10.015] [PMID]

[19] Hislop HJ, Montgomery J. Daniels and worthingham's muscle testing: Techniques of manual examination. Welwyn Garden City: Saunders; 2009.

[20] Verschuren O, Ketelaar M, Takken T, Van Brussel M, Helders PJ, Gorter JW. Reliability of hand-held dynamometry and functional strength tests for the lower extremity in children with Cerebral Palsy. Disability and Rehabilitation. 2008; 30(18):1358-66. [DOI:10.1080/09638280701639873] [PMID]

[21] Portney LG, Watkins MP. Foundations of clinical research: Applications to practice. Upper Saddle River, New Jersey: Prentice Hall; 2009.

[22] Crompton J, Galea MP, Phillips B. Hand-held dynamometry for muscle strength measurement in children with Cerebral Palsy. Developmental Medicine \& Child Neurology. 2007; 49(2):10611. [DOI:10.1111/j.1469-8749.2007.00106.x] [PMID]

[23] Schrama PP, Stenneberg MS, Lucas C, van Trijffel E. Intraexaminer reliability of hand-held dynamometry in the upper extremity: A systematic review. Archives of Physical Medicine and Rehabilitation. 2014; 95(12):2444-69. [DOI:10.1016/j. apmr.2014.05.019] [PMID]

[24] Damiano DL, Dodd K, Taylor NF. Should we be testing and training muscle strength in Cerebral Palsy? Developmental Medicine and Child Neurology. 2002; 44(1):68-72. [DOI:10.1017/ S0012162201001682] [PMID]

[25] Berg-Emons RJ, Baak MA, Barbanson DC, Speth L, Saris WH. Reliability of tests to determine peak aerobic power, anaerobic power and isokinetic muscle strength in children with spastic Cerebral Palsy. Developmental Medicine \& Child Neurology. 1996; 38(12):1117-25. [DOI:10.1111/j.1469-8749.1996.tb15075.x] 